\title{
Increasing Interference of Stray and Wild Animals in Farming: Reflections from Western Himalayan Foothills
}

\author{
Rajesh Kumar Thakur, Aditi Walia, Kanika Mehta, Virender Kumar and Harbans Lal \\ Department of Agricultural Economics, Extension Education \& Rural Sociology \\ CSK Himachal Pradesh Krishi Vishvavidyalya, Palampur-176 062, India
}

E-mail: rkthakurkvk@yahoo.co.in

\begin{abstract}
The problem of animal menace is a burning issue and has direct bearing on the socio-economic conditions of the people in general and farming community in particular. Therefore, the present study was conducted to examine the various aspects of animal menace such as animal species responsible, frequency of crop raiding, extent and degree of menace and crop damages. The study is based on the primary data collected from 60 farm households selected through three stage random sampling technique in Kangra district of Himachal Pradesh. The results revealed that cattle, monkey, wild boar, sambar and nilgai were the major animal species associated with crop damages. Among these, the problem of cattle was reported to be of relatively recent origin (2-5 years) compared to wild animals' menace (5-10 years). During 20092015 , there had been a significant increase in animal population from 1.68 to 8.53 in case of stray cattle and 5.66 to 29.48 for wild animals with monkey as dominant species. As far as degree of menace was concerned, the problem of wild animals was more serious compared to the stray cattle. Further, among the wild animals the degree of monkey menace was the major concern round the year.
\end{abstract}

Keywords: Animal menace, Crop damage, Crop raiding, Stray cattle, Wild animals

Agriculture is the major source of livelihood for the majority of rural population in mountainous regions of India where the farming community generally practices mixed farming to meet their multifarious demands. With the advancement of agricultural technology and extension services, the production and income generating potential of traditional farming systems have improved through the diversification and intensification. Despite of farmers' efforts and public safety nets, farming still remains a risky venture. Since the inhabited villages and farming lands are surrounded by forests, rivulets and gorges which are natural hideouts for wild animals (monkey, sambar, wild boar, nilgai, etc.) and the fragmentation of forest lands has led to the constant increase in the human- animal conflict (Saraswathi et al 2021).Due to changes in techno-socio-economic conditions in these regions, abandoning unproductive cattle (mainly bullocks) has become a common practice. The increasing population of these animals has assumed the form of menace for the farming.

Animal menace has become one of the major threats for growth and sustainability of agriculture and its extent varies from region to region depending upon the prevalence of animal species and their population status. Among these animals, the problems of menace associated with monkeys (Chauhan and Pirta 2010, Saraswat et al 2015, Reddy and Chander 2016, Rathi and Bhatt 2020) and stray cattle (Arya et al 2019, Lal et al 2019) are more widespread and serious compared to others. In Himachal Pradesh there are 3243 panchayats out of which about 71 per cent are suffering from monkey menace and the population of stray cattle is around 32160 . The conservative estimates of wildlife wing of Himachal Pradesh indicated an annual loss of worth Rs $300-450$ crore in the horticulture and agriculture sectors on account of animal menace which may go upto Rs 1,500 crore if expenditure on watch and ward of crops is also accounted for. The crop loss, livestock loss and human injury or even deaths have also been reported (Karanth et al 2013). The farmers are abandoning cultivation due to stray and wild animal menace. Thus, the problem of animal menace is a burning issue and has direct bearing on the socio-economic conditions of the people in general and farming community in particular. Dev et al (2019) also reported that the problem of animal menace in Himachal Pradesh was limiting the farmers from effective use of advanced technologies. The problem needs to be tackled in a planned and systematic manner after examining and identifying the causes and key factors responsible for the ever increasing animal menace at local or regional levels. Thus, a diagnostic analysis on animal menace especially with respect to its origin, animals associated, degree of menace and extent of crop losses was conducted to provide insights for effective planning and management of animal menace at farmer and government level. 


\section{MATERIAL AND METHODS}

The present investigation had been conducted in foothills of Western Himalayan region. The Kangra district of Himachal Pradesh was purposively selected for the study as it represents the average situation of the region with respect to agro-climatic conditions and has the highest number of holdings \& stray cattle population among different districts of Himachal Pradesh. The study is based on the primary data collected from farming households selected through three stage random sampling design (blocks, villages and farmers). Finally, a sample of 60 farming households was drawn from the ten villages by adopting equal allocation method. Detailed information about the origin of the animals menace, major animals responsible for crop damages, trend of the wild/stray animal population, extent of crop damages, etc. were collected from the respondents. The data were collected through personal survey method on specifically designed and pre-tested survey schedules. The data were analysed by using simple tabular method, percentages, averages and total weighted score for the interpretation of results.

\section{RESULTS AND DISCUSSION}

Origin of animal menace: The responses indicated that the problem of stray cattle was of recent origin as compared to wild animals (Table 1). The majority of respondents (62\%) revealed that the problem of stray cattle had become more serious between last 2-5 years. It may be attributed to the fact that the farmers no longer wanted to rear bullocks (being replaced by tractors and power tillers) and cattles with low productivities and abandoned them. The problem of wild animals was not serious about over 10 years back. About 67 per cent of the respondents reported that these had become more prominent during last 5- 10 years. This could be attributed to the shrinkage of fodder and other food species in forests forcing the wild animals to raid the cultivated lands (Anonymous 2012).

Animals involved in menace: The prevalence of wild animals responsible for crop losses varied from area to area. The monkey, wild boar, sambar and nilgai were reported to be the major wild animals responsible for crop damages (Chhangani et al 2008). About 48, 37 and 28 per cent of the respondents reported problems due to monkey, wild boar and sambar, respectively, while 25 per cent of the respondents encountered the problem from other wild animals such as nilgai (Table 2). The problem of stray cattle was reported by about 42 per cent of the sample households. The figures given in the table are with respect to major animal species responsible for menace; however, in some areas more than one species might have also caused losses.
Population pattern of stray and wild animals: The crop damages and extent of losses depends on the population of animals (wild \& stray cattle) prevalent in the locality. Their population might increase or decrease in a particular area. According to the sample respondents, over the period of 2009 to 2015, there had been an increase in population of wild and stray animal raiding the crops (Table 3 ). The total population of wild animals prevalent in the study area (2015) was estimated at 29.48 in which the proportion of monkeys was found to be highest (55.51\%) followed by wild boar and sambar. The population of monkeys was comparatively more as compared to the other wild animals mainly because they are not hunted/killed by the locals on account of religious reasons. Saraswat et al (2015) also observed the Humanrhesus macaque monkey conflict as a major problem affecting northern India, particularly the states of Himachal Pradesh and Uttarakhand. Similarly the population of stray cattle increased from 1.68 during 2009 to 8.53 in 2015. The population of wild animals, especially monkeys and stray cattle, is increasing continuously and may have adverse impact on farming in the years to come.

Herd size of animals: Larger the size of herd, higher will be the extent of crop damages. It was reported by the majority of respondents that total population of herd prevalent in an area was not important for crop losses but the extent of damage is usually directly related with the number of animals actually raiding the crops (Table 4 ). It was found that among the

Table 1. Response of farmers regarding origin of animal menace

\begin{tabular}{lcc}
\hline Particulars & \multicolumn{2}{c}{ Number } \\
\cline { 2 - 3 } & Wild animals & Stray animals \\
\hline 2yr back & - & - \\
$2-5$ yr back & $16(26.67)$ & $37(61.67)$ \\
$5-10$ yr back & $40(66.67)$ & $23(38.33)$ \\
$>10$ yrs & $4(6.67)$ & - \\
Total & $60(100.00)$ & $60(100.00)$ \\
\hline
\end{tabular}

Figures in parentheses indicate percentages to total in each category

Table 2. Distribution of respondents with respect to animals responsible for menace

\begin{tabular}{lcc}
\hline Particulars & Number & Per cent \\
\hline Wild animals & & \\
Monkey & 29 & 48.33 \\
Sambar & 17 & 28.33 \\
Wild boar & 22 & 36.67 \\
Any other (Nilgai) & 15 & 25.00 \\
Stray animals & & \\
Cattle & 25 & 41.67 \\
\hline
\end{tabular}


different animals, the herd size raiding the fields was found to be highest in case of monkeys (7.50) ranging from 5-12 in number followed by cattle (3.78) and wild boar (3.28) ranging from 3-6 and 2-6, respectively. However, the crop raiding by other animals like Sambar and Nilgai was comparatively lower. Though the animal population in the locality was more yet they attacked in smaller numbers. The smaller groups might allow them to easily escape from the fields after causing the damage to the crop fields.

Resting and entry points for wild/stray animals: Majority of respondents mentioned that animals enter the village and (or) farmers' fields through some common entry points. As the number of entry points leading to the crop fields increases the entry of crop raiding animals becomes easy and safe, while watch \& ward of crop fields become difficult. It was also observed that the fragments nearer to the entry points were more prone to damage as compared to the fragments situated far away from the entry points. Monney et al (2010) recommended growing of plants that are undesirable to the animals close to the boundary to act as buffer. It was found that on an average there were about 3.6 and 2.4 entry points for wild and stray animals, respectively in the sample villages. It was reported by majority of respondents that these animals usually rest at some preferred places in the villages in case of stray cattle and nearby hideouts in case of wild animals. The total number of resting or hiding places was found to be about three in case of stray cattle whereas there was no common resting/hiding spot near fields/ villages in case of wild animals.

Frequency and time of visit of wild and stray animal: The study revealed that the animals visited the fields at different crop stages as per their preferences. Stray cattle, sambar and nilgai visited the fields in any of the crop growth stages as they feed on the vegetative growth but wild boar and monkeys feed on tubers, maize cobs, etc. and usually raided and damaged the crops at reproductive stages. In case of wild animals, monkey damaged the fields during the day time while other wild animals such as wild boar, sambar and nilgai raided the fields during the night time, whereas both the day and night hours were preferred by the stray cattle for raiding the crop fields (Table 5). Wild/stray animals visited the crop

Table 4. Average size of herd raiding crop fields on sample farms

\begin{tabular}{lcc}
\hline Particulars & Number & Range (Number) \\
\hline Wild animal & & \\
Monkey & 7.50 & $5-12$ \\
Wild boar & 3.28 & $2-6$ \\
Sambar & 1.42 & $2-5$ \\
Other (Nilgai) & 0.75 & $1-4$ \\
Stray animal & & \\
Cattle & 3.78 & $3-6$ \\
\hline
\end{tabular}

Table 5. Farmers' response regarding frequency of crop raiding by wild and stray animals

(Weekly)

\begin{tabular}{lccccc}
\hline Crop raiding & \multicolumn{2}{c}{ Day } & & \multicolumn{2}{c}{ Night } \\
\cline { 2 - 3 } \cline { 5 - 6 } Wild animals & No. & Percentage & & No. & Percentage \\
\hline Once & 32 & 53.33 & & 37 & 61.67 \\
Twice & 24 & 40.00 & & 20 & 33.33 \\
$>$ Twice & 4 & $(6.67$ & & 3 & 5.00 \\
Total & 60 & 100.00 & & 60 & 100.00 \\
Stray animals & & & & \\
Once & 33 & 55.00 & & 34 & 56.67 \\
Twice & 25 & 41.67 & & 24 & 40.00 \\
$>$ Twice & 2 & 3.33 & & 2 & 3.33 \\
Total & 60 & 100.00 & & 60 & 100.00 \\
\hline
\end{tabular}

Table 3. Pattern of population of stray and wild animals in study area

\begin{tabular}{|c|c|c|c|c|c|c|c|}
\hline Year & Monkey & Wild Boar & Sambar & Other & Sub-total & Stray animal & Total \\
\hline 2009 & $\begin{array}{c}3.75 \\
(51.09)\end{array}$ & $\begin{array}{c}1.27 \\
(17.30)\end{array}$ & $\begin{array}{c}0.52 \\
(7.08)\end{array}$ & $\begin{array}{c}0.12 \\
(1.63)\end{array}$ & $\begin{array}{c}5.66 \\
(77.11)\end{array}$ & $\begin{array}{c}1.68 \\
(22.89)\end{array}$ & $\begin{array}{c}7.34 \\
(100.00)\end{array}$ \\
\hline 2010 & $\begin{array}{c}6.50 \\
(54.90)\end{array}$ & $\begin{array}{c}1.47 \\
(12.42)\end{array}$ & $\begin{array}{c}0.77 \\
(6.50)\end{array}$ & $\begin{array}{c}0.32 \\
(2.70)\end{array}$ & $\begin{array}{c}9.06 \\
(76.52)\end{array}$ & $\begin{array}{c}2.78 \\
(23.48)\end{array}$ & $\begin{array}{c}11.84 \\
(100.00)\end{array}$ \\
\hline 2011 & $\begin{array}{c}10.08 \\
(59.12)\end{array}$ & $\begin{array}{c}2.20 \\
(12.90)\end{array}$ & $\begin{array}{c}0.83 \\
(4.87)\end{array}$ & $\begin{array}{c}0.32 \\
(1.88)\end{array}$ & $\begin{array}{c}13.43 \\
(78.77)\end{array}$ & $\begin{array}{c}3.62 \\
(21.23)\end{array}$ & $\begin{array}{c}17.05 \\
(100.00)\end{array}$ \\
\hline 2012 & $\begin{array}{c}15.83 \\
(61.21)\end{array}$ & $\begin{array}{c}2.83 \\
(10.94)\end{array}$ & $\begin{array}{c}1.08 \\
(4.18)\end{array}$ & $\begin{array}{c}0.67 \\
(2.59)\end{array}$ & $\begin{array}{c}20.41 \\
(78.92)\end{array}$ & $\begin{array}{c}5.45 \\
(21.08)\end{array}$ & $\begin{array}{c}25.86 \\
(100.00)\end{array}$ \\
\hline 2013 & $\begin{array}{c}18.57 \\
(60.87)\end{array}$ & $\begin{array}{c}3.18 \\
(10.42)\end{array}$ & $\begin{array}{c}1.58 \\
(5.18)\end{array}$ & $\begin{array}{c}0.9 \\
(2.95)\end{array}$ & $\begin{array}{c}24.23 \\
(79.42)\end{array}$ & $\begin{array}{c}6.28 \\
(20.58)\end{array}$ & $\begin{array}{c}30.51 \\
(100.00)\end{array}$ \\
\hline 2014 & $\begin{array}{c}19.08 \\
(56.72)\end{array}$ & $\begin{array}{c}4.50 \\
(13.38)\end{array}$ & $\begin{array}{c}1.78 \\
(5.29)\end{array}$ & $\begin{array}{c}1.08 \\
(3.21)\end{array}$ & $\begin{array}{c}26.44 \\
(78.60)\end{array}$ & $\begin{array}{c}7.20 \\
(21.40)\end{array}$ & $\begin{array}{c}33.64 \\
(100.00)\end{array}$ \\
\hline 2015 & $\begin{array}{l}21.10 \\
(55.51)\end{array}$ & $\begin{array}{c}4.82 \\
(12.68)\end{array}$ & $\begin{array}{c}2.13 \\
(5.60)\end{array}$ & $\begin{array}{c}1.43 \\
(3.76)\end{array}$ & $\begin{array}{c}29.48 \\
(77.56)\end{array}$ & $\begin{array}{c}8.53 \\
(22.44)\end{array}$ & $\begin{array}{c}38.01 \\
(100.00)\end{array}$ \\
\hline
\end{tabular}

Figures in parentheses indicate percentages to total in each category 
fields once in a week during the day and night time. About 40 and 33 per cent of the respondents reported that wild animals' raided the field twice a week during day and night time, respectively. It was observed that the stray cattle raided the fields once a week and preferably during the night hours. Only 3.33 per cent of the respondents informed that stray cattle raided the fields more than twice. Thus, it can be concluded that crop fields were raided usually once a week by stray and wild animals during the night hours, as it was easier to raid the crops during the night hours.

Degree of menace by different animals: The degree of animal menace in the study area was not uniform; it varied with type of animals prevalent in a particular area (Table 6). It was observed that 30 and 33 per cent of the sample respondents were facing the problem of stray cattle and wild animals, respectively, while about 37 per cent of the sample respondents were having the problem of stray and wild animals both. The problem of wild animals was rated as of high degree by about 50 per cent of the farmers. Majority of farmers having the problem of stray cattle and wild animal menace rated it asof moderate (50\%) and high degree (38.89 $\%)$. About 55 and 27 per cent of the sample farmers facing problems with both categories of animals reported the problem as of medium and high degree, respectively. The highest total weighted score i.e. 47 was observed in case of wild animals followed by both wild/ stray animal problem (46). This indicated that the problem of wild animals was more serious in areas compared to stray animals.

Seasonal pattern and degree of crop damage by animals: The pattern of crop raiding by stray and wild animals was not uniform throughout the year. It was reported to be influenced by the availability of fodder in common land, forests as well as crop stand in the agricultural fields. The fodder availability in the forests/common lands in summer and winter months was usually less and there were more chances of wild and stray animals raiding the field crops. The respondents were enquired about the degree of animal menace in different seasons of the years and the responses have been depicted in Table 7. Depending on the degree of problem, the crop raiding animals were ranked on the basis of total weighted score. The total weighted score was computed by assigning weight; 1, 2 and 3 for low, medium and high degree of problem, respectively. The analysis revealed that in summer and winter season the total weighted score was highest in case of monkey, thus the damage by monkey was more serious in these seasons followed by stray cattle, whereas the total weighted score was highest for wild boar during the rainy season, thus it caused maximum problem during this season. Rao et al (2015) have also reported enormous damage by wild boar in Southern India. In general the problem of animal menace in case of sambar, stray cattle, nilgai was found to be low in rainy season, mainly because ample fodder was available for these animals in areas other than crop fields. Similar analysis of seasonal crop raiding was also done by Prashanth et al (2013)and Warren et al (2007).

Degree of crop damage at different crop stages: The frequency of crop raids by a particular animal depends upon the preferred crops and preferred crop stages (vegetative, reproductive \& maturity) of a particular crop. Among the different categories of crops viz. cereals, pulses, oilseeds, fodder and vegetable crops; cereals were more preferred crops by the wide range of wild and stray animals as compared to others because these crops provided fodder as well as grains of their preference. Thus, these were raided by sambar, nilgai and stray cattle throughout the entire growth period; while monkey preferred these crops especially maize at reproductive and maturity stages. Sahoo and Mohnot (2004)also specified that the major agricultural crops targeted by monkeys in Himachal Pradesh were maize, potato, wheat, vegetables and pulses and horticultural crops like apple, pear, cherries, plum, almond, walnut and apricot (Table 8, 9). Khatun et al (2013) also observed the extensive

Table 6. Degree of animal menace on sample farms

\begin{tabular}{|c|c|c|c|c|c|c|}
\hline Particulars & $\mathrm{L}$ & $M$ & $\mathrm{H}$ & Total & TWS & Rank \\
\hline \multirow[t]{2}{*}{ Wild animal } & 3 & 7 & 10 & 20 & 47 & I \\
\hline & $(15.00)$ & $(35.00)$ & $(50.00)$ & (33.33) & - & - \\
\hline \multirow[t]{2}{*}{ Stray cattle } & 2 & 9 & 7 & 18 & 41 & III \\
\hline & (11.11) & $(50.00)$ & $(38.89)$ & $(30.00)$ & - & - \\
\hline \multirow[t]{2}{*}{ Both } & 4 & 12 & 6 & 22 & 46 & II \\
\hline & (18.18) & $(54.55)$ & $(27.27)$ & (36.67) & - & - \\
\hline \multirow[t]{3}{*}{ Total } & 9 & 28 & 23 & 60 & - & - \\
\hline & $(15.00)$ & (46.67) & (38.33) & $(100.00)$ & - & - \\
\hline & $(100.00)$ & $(100.00)$ & $(100.00)$ & $(100.00)$ & - & - \\
\hline
\end{tabular}

$\mathrm{L}=$ Low, $\mathrm{M}=$ Moderate, $\mathrm{H}=$ High, $\mathrm{TWS}=$ Total weighted score

Figures in parentheses indicate percentages to total in each category 
Table 7. Degree of menace by important animals during different seasons on sample farms

\begin{tabular}{|c|c|c|c|c|c|c|c|c|c|c|}
\hline \multirow[t]{2}{*}{ Season/Animal } & \multicolumn{2}{|c|}{ Low } & \multicolumn{2}{|c|}{ Medium } & \multicolumn{2}{|c|}{ High } & \multicolumn{2}{|c|}{ Total } & \multirow[t]{2}{*}{ TWS } & \multirow[t]{2}{*}{ Rank } \\
\hline & No. & $\%$ & No. & $\%$ & No. & $\%$ & No. & $\%$ & & \\
\hline \multicolumn{11}{|l|}{ Summer } \\
\hline Monkey & 3 & 10.34 & 7 & 24.14 & 19 & 65.52 & 29 & 100.00 & 74 & I \\
\hline Sambar & 5 & 29.41 & 4 & 23.53 & 8 & 47.06 & 17 & 100.00 & 37 & IV \\
\hline Wild boar & 5 & 22.73 & 7 & 31.82 & 10 & 45.45 & 22 & 100.00 & 49 & III \\
\hline Cattle & 2 & 8.00 & 5 & 20.00 & 18 & 72.00 & 25 & 100.00 & 66 & II \\
\hline Other & 2 & 13.33 & 5 & 33.33 & 8 & 53.33 & 15 & 100.00 & 36 & V \\
\hline \multicolumn{11}{|l|}{ Winter } \\
\hline Monkey & 2 & 6.90 & 12 & 41.38 & 15 & 51.72 & 29 & 100.00 & 71 & I \\
\hline Sambar & 2 & 11.76 & 5 & 29.41 & 10 & 58.82 & 17 & 100.00 & 42 & IV \\
\hline Wild boar & 2 & 9.09 & 9 & 40.91 & 11 & 50.00 & 22 & 100.00 & 53 & III \\
\hline Cattle & 1 & 4.00 & 10 & 40.00 & 14 & 56.00 & 25 & 100.00 & 63 & II \\
\hline Other & 1 & 6.67 & 4 & 26.67 & 10 & 66.67 & 15 & 100.00 & 39 & V \\
\hline \multicolumn{11}{|l|}{ Rainy } \\
\hline Monkey & 20 & 68.97 & 7 & 24.14 & 2 & 6.90 & 29 & 100.00 & 40 & I \\
\hline Sambar & 11 & 64.71 & 3 & 17.65 & 3 & 17.65 & 17 & 100.00 & 26 & IV \\
\hline Wild boar & 11 & 50.00 & 5 & 22.73 & 6 & 27.27 & 22 & 100.00 & 39 & II \\
\hline Cattle & 20 & 80.00 & 5 & 20.00 & - & - & 25 & 100.00 & 30 & III \\
\hline Other & 9 & 60.00 & 6 & 40.00 & - & - & 15 & 100.00 & 21 & $\mathrm{~V}$ \\
\hline
\end{tabular}

TWS=Total Weighted Score

Table 8. Extent of crop damage by different animals at vegetative stage on sample farms

\begin{tabular}{|c|c|c|c|c|c|c|c|}
\hline \multirow[t]{2}{*}{ Particulars } & \multicolumn{7}{|c|}{ Damage } \\
\hline & $N$ & L & $M$ & $\mathrm{H}$ & Total & TWS & Rank \\
\hline \multicolumn{8}{|l|}{ Cereals } \\
\hline \multirow[t]{2}{*}{ Monkey } & 55 & 5 & - & - & 60 & 5 & V \\
\hline & $(91.67)$ & (8.33) & - & - & $(100.00)$ & & \\
\hline \multirow[t]{2}{*}{ Wild Boar } & 38 & 20 & 2 & - & 60 & 24 & III \\
\hline & (63.33) & (33.33) & (3.33) & - & $(100.00)$ & & \\
\hline \multirow[t]{2}{*}{ Sambar } & 43 & 5 & 12 & - & 60 & 29 & II \\
\hline & (71.67) & $(8.33)$ & $(20.00)$ & - & $(100.00)$ & & \\
\hline \multirow[t]{2}{*}{ Cattle } & 35 & 5 & 20 & - & 60 & 45 & I \\
\hline & $(58.33)$ & $(8.33)$ & (33.33) & - & $(100.00)$ & & \\
\hline \multirow[t]{2}{*}{ Other } & 45 & 9 & 6 & - & 60 & 21 & IV \\
\hline & $(75.00)$ & (15.00) & $(10.00)$ & - & $(100.00)$ & & \\
\hline \multicolumn{8}{|l|}{ Vegetables } \\
\hline \multirow[t]{2}{*}{ Monkey } & 31 & 22 & 7 & - & 60 & 36 & II \\
\hline & $(51.67)$ & $(36.70)$ & $(11.70)$ & - & $(100.00)$ & & \\
\hline \multirow[t]{2}{*}{ Wild Boar } & 38 & 16 & 6 & - & 60 & 28 & III \\
\hline & $(63.30)$ & $(26.70)$ & $(10.00)$ & - & $(100.00)$ & & \\
\hline \multirow[t]{2}{*}{ Sambar } & 43 & 12 & 5 & - & 60 & 22 & IV \\
\hline & $(71.70)$ & $(20.00)$ & $(8.33)$ & - & $(100.00)$ & & \\
\hline \multirow[t]{2}{*}{ Cattle } & 35 & 10 & 15 & - & 60 & 40 & I \\
\hline & $(58.30)$ & $(16.70)$ & $(25.00)$ & - & $(100.00)$ & & \\
\hline \multirow[t]{2}{*}{ Other } & 45 & 10 & 5 & - & 60 & 20 & $\mathrm{~V}$ \\
\hline & $(75.00)$ & (16.70) & (8.33) & - & $(100.00)$ & & \\
\hline
\end{tabular}

$\mathrm{N}=\mathrm{Nil}, \mathrm{L}=\mathrm{Low}, \mathrm{M}=$ Moderate, $\mathrm{H}=$ High, TWS= Total weighted score Figures in parentheses indicate percentages to total in each category 
Table 9. Extent of crop damage by different animals at reproductive and maturity stage

\begin{tabular}{|c|c|c|c|c|c|c|c|}
\hline \multirow{2}{*}{ Particulars } & \multicolumn{7}{|c|}{ Damage } \\
\hline & $\mathrm{N}$ & $\mathrm{L}$ & $M$ & $\mathrm{H}$ & Total & TWS & Rank \\
\hline \multicolumn{8}{|l|}{ Cereals } \\
\hline \multirow[t]{2}{*}{ Monkey } & 31 & - & 2 & 27 & 60 & 85 & I \\
\hline & $(51.70)$ & - & (3.33) & $(45.00)$ & $(100.00)$ & & \\
\hline \multirow[t]{2}{*}{ Wild Boar } & 38 & - & 4 & 18 & 60 & 62 & III \\
\hline & $(63.30)$ & - & $(6.67)$ & $(30.00)$ & $(100.00)$ & & \\
\hline \multirow[t]{2}{*}{ Sambar } & 43 & - & 3 & 14 & 60 & 48 & IV \\
\hline & $(71.70)$ & - & $(5.00)$ & $(23.30)$ & $(100.00)$ & & \\
\hline \multirow[t]{2}{*}{ Cattle } & 35 & - & 3 & 22 & 60 & 72 & II \\
\hline & $(58.30)$ & - & $(5.00)$ & $(36.70)$ & $(100.00)$ & & \\
\hline \multirow[t]{2}{*}{ Other } & 45 & - & 4 & 11 & 60 & 41 & V \\
\hline & $(75.00)$ & - & $(6.67)$ & $(18.30)$ & $(100.00)$ & & \\
\hline \multicolumn{8}{|l|}{ Vegetables } \\
\hline \multirow[t]{2}{*}{ Monkey } & 31 & - & 7 & 22 & 60 & 80 & I \\
\hline & $(51.70)$ & - & $(11.70)$ & $(36.70)$ & $(100.00)$ & & \\
\hline \multirow[t]{2}{*}{ Wild Boar } & 38 & - & 6 & 16 & 60 & 60 & III \\
\hline & $(63.30)$ & - & $(10.00)$ & $(26.70)$ & $(100.00)$ & & \\
\hline \multirow[t]{2}{*}{ Sambar } & 43 & - & 5 & 12 & 60 & 46 & IV \\
\hline & $(71.70)$ & - & (8.33) & $(20.00)$ & $(100.00)$ & & \\
\hline \multirow[t]{2}{*}{ Cattle } & 35 & - & 10 & 15 & 60 & 65 & II \\
\hline & $(58.30)$ & - & $(16.70)$ & $(25.00)$ & (100.00) & & \\
\hline \multirow[t]{2}{*}{ Other } & 45 & - & 3 & 12 & 60 & 42 & V \\
\hline & $(75.00)$ & - & $(5.00)$ & $(20.00)$ & $(100.00)$ & & \\
\hline
\end{tabular}

$\mathrm{N}=\mathrm{Nil}, \mathrm{L}=\mathrm{Low}, \mathrm{M}=$ Moderate, $\mathrm{H}=$ High, $\mathrm{TWS}=$ Total weighted score

Figures in parentheses indicate percentages to total in each category

damage of fruit crops by monkeys in Bangladesh.

Vegetative growth stages: The vegetative stage suffered damage on account of trampling by monkeys and eating of leaves by wild boar, sambar, nilgai and stray cattle. In this stage, low level of damage in cereals by monkeys was reported by about eight per cent of respondents while it was of medium level in case of wild boar, sambar and stray cattle as indicated by about 3, 20 and 33 per cent of the respondents, respectively. In case of vegetables, about 37 , 27, 20, 17 and 17 per cent of the respondents reported low degree damage by monkey, wild boar, sambar, stray cattle and others, respectively. The magnitude of TWS for different animals indicated that during vegetative crop stage stray cattle was at rank-I as far as losses to the crops were concerned. On the other hand, monkey was the least damaging at this crop stage.

Reproductive and maturity stage: In case of cereals and vegetables, damage to crops was both by trampling and consumption of vegetative parts of cereals and vegetables by animals. Among all the stages of cereals, reproductive and the maturity stages were the most vulnerable to damage by animals. About 45, 30, 23, 37 and 18 per cent of the respondents reported high damage during the maturity and reproductive stage in cereals by monkey, wild boar, sambar, cattle and others animals, respectively. In case of vegetables about $37,27,20,25$ and 20 per cent of the respondents reported high damage by monkey, wild boar, sambar, stray cattle and others animals, respectively. The crop damages by monkeys were reported to be highest for both the cereals and vegetables during the reproductive and maturity stages followed by cattle, wild boar, sambar and other animals.

\section{CONCLUSION}

In the recent years the animal menace has emerged as a major threat for the sustainability and progress of farming in hilly regions. The study revealed that monkey, wild boar, sambar, nilgai and stray cattle were major animals responsible for crop losses. The problem of stray cattle was relatively of recent origin compared to wild animals. Although the animal population was high yet the size of herd raiding 
fields and damaging crops was relatively small. The frequency of crop raiding by wild and stray animals was once a week. As far as the degree of menace was concerned, half of the respondents felt that the menace of wild animals was of high degree while it was of medium category for stray cattle, which indicated that menace of wild animals was the major issue in the study area. The season wise analysis of the degree of menace indicated that among the major animals, monkey was reported to be the highly crop damaging animal in all the seasons (summer, winter and rainy). Next to monkey, stray cattle in summer and winter seasons and wild boar in rainy season were reported as major animals responsible for menace. Stray cattle, sambar and nilgai were damaging the crops during all stages while monkey and wild boars damaged the crops during reproductive/maturity crop stage. In vegetative growth stage of cereals and vegetables, cattle caused highest loss to crops while during reproductive and maturity stages of the cereals and vegetables, monkey were responsible for highest extent of losses. Thus, these findings can be used in tackling the growing problem of animal menace to keep alive the avocation of farming in hills.

\section{REFERENCES}

Anonymous 2012. $19^{\text {th }}$ Livestock Census 2012. All India report: Ministry of Agriculture, Department of Animal Husbandry, Dairying \& Fisheries, Krishi Bhawan, New Delhi, India.

Arya S, Swain RK, Nayak HK and Pati AK 2019. Circadian variations in foraging and resting/standing activity patterns of stray street cattle of urban Sambalpur, Odisha, India. Biological Rhythm Research 51(7): 1-13.

Chauhan A and Pirta RS 2010. Public opinion regarding humanmonkey conflict in Shimla, Himachal Pradesh. Journal of Human Ecology 30(2): 105-109.

Chhangani AK, Robbins $P$ and Mohnot SM 2008. Crop raiding and livestock predation at Kumbhalgarh wildlife sanctuary, Rajasthan, India. Human Dimensions of Wildlife 13(5): 305-316.

Dev K, Sharma R and Guleria A 2019. Impact of mid-Himalayan watershed development project on employment, income generation and problems faced by farmer's in Himachal
Pradesh. Indian Journal of Ecology 46(4): 938-942.

Karanth KK, Gopalaswamy AM and Dasgupta PK 2013. Patterns of human-wildlife conflicts and compensation: Insights from Western Ghats protected areas. Biological Conservation 166: 175-185.

Khatun UH, Ahsan MF and Roskaft E 2013. Local people's perceptions of crop damage by common langurs and humanlangur conflict in Keshabpur of Bangladesh. Environment and Natural Resources Research 3(1): 111-112.

Lal SP, Jha SK and Sinha S 2019. Detrimental bio-invasion in the green revolution belt of India: LSD multiple comparisons post hoc analysis. Journal of Entomology and Zoology Studies 7(2): 129-132.

Monney KA, Dakwa KB and Wiafe ED 2010. Assessment of crop raiding situation by elephants in farms around Kakum conservation area, Ghana. International Journal of Biodiversity and Conservation 2(9): 243-249.

Prashanth PKM, Kumara V and Thirumala S 2013. Man - animal conflicts in protected areas: A case study of Gaur, BosGaurus H Smith from the Mookambika wildlife sanctuary, Kollur, Karnataka, India. International Journal of Current Microbiology and Applied Sciences 2(12): 466-475.

Rao VV, Naresh B, Reddy VR, Sudhakar C, Venkateswarlu P and Rao DR 2015. Traditional management methods used to minimize wild boar (Sus scrofa) damage in different agricultural crops at Telangana state, India. International Journal of Multidisciplinary Research and Development 2(2): 32-36.

Rathi $R$ and Bhatt D 2020. Human-monkey conflict in human dominated landscape of Najibabad forest division, Bijnor. Indian Journal of Animal Sciences 90(5): 788-791.

Reddy Aand Chander J 2016. Human-monkey conflict in India: Some available solutions for conflict mitigation with special reference to Himachal Pradesh. Indian Forester 142(10): 941-832.

Sahoo SK and Mohnot SM 2004. A survey of crop damage by rhesus monkey (Macaca mulatta) and human langur (Semnopithecus entellus) in Himachal Pradesh, India. Tiger Paper 31(4): 1-5.

Saraswat R, Sinha A and Radhakrishna S 2015. A god becomes a pest? Human-rhesus macaque interactions in Himachal Pradesh, Northern India. European Journal of Wildlife Research 61(3): 435-443.

Saraswathi VS, Johnson M and Kumaraguru A 2021. Review on water holding capacity of soil across the tropical and subtropical forests in India. Indian Journal of Ecology 48(3): 641-648.

Warren Y, Buba B and Ross C 2007. Patterns of crop-raiding by wild and domestic animals near Gashaka Gumti National Park, Nigeria. International Journal of Pest Management 53(3): 207216. 